\title{
Pemanfaatan After Effects Motion Graphics untuk Membantu Strategi Komunikasi Program Inovasi Kasih Jeruk Purut
}

\author{
Prita Suci Nurcandrani ${ }^{\text {a, } 1, * \text {, Rizki Ardhi Rahman }}{ }^{\text {b,2 }}$, Bumi Bidadari Shaskia ${ }^{b, 3}$ \\ ${ }^{\mathrm{a}, \mathrm{b}}$ Program Studi Ilmu Komunikasi Universitas Amikom, Jl. Letjen Pol Sumarto Watumas Purwanegara, Purwokerto \\ ${ }^{1}$ prita.suci@ amikompurwokerto.ac.id *; ${ }^{2}$ rizkiardhi2@ gmail.com; ${ }^{3}$ bumibidadari@ gmail.com \\ * corresponding author
}

ARTICLE INFO

Article History

Received,01-09-2020

Revised,10-01-2021

Accepted,18-01-2021

Keywords

After Effects Motion

Graphics;

Communication Aids:

Exclusive Breastfeeding

\begin{abstract}
The Banyumas Regency Health Office summarized that in 2019, stunting in the North Purwokerto Subdistrict area reached 261 cases. In the same time, the infant mortality rate in Banyumas Regency reached 127 cases including four cases were occured in the work area of North Purwokerto II. The Kasih Jeruk Purut Program aims to increase the coverage of exclusive breastfeeding to more than $90 \%$ in the work area of the Puskesmas Purwokerto Utara II with the main objective is to reduce infant mortality and prevent stunting. The socialization activities carried out require tools to facilitate effective communication to occur. Communication aids in the form of brochures or leaflets provided by the central government often did not meet the target program effectively because the brochures contained too many written elements. The purpose of this PKM is to help provide effective After Effects Motion Graphics to assist the implementation of the Kasih Jeruk Purut Program. The design of the implementation media design for The Kasih Jeruk Purut Program is in the form of a simple Motion Graphics design containing the content of the right breastfeeding method. After making After Effects Motion Graphic, it was continued with the socialization of this application to the head of the program and the Kasih Jeruk Purut team, and tested it on patients and continued with evaluation.
\end{abstract}

\section{PENDAHULUAN}

Stunting merupakan gangguan pertumbuhan yang diakibatkan kekurangan asupan gizi kronik serta disebabkan karena terjadinya infeksi yang berulang terutama pada seribu hari pertama kehidupan (HPK). Anak dapat dikatakan stunting apabila panjang atau tinggi badannya berada di bawah minus dua standar deviasi panjang atau tinggi anak seusianya. Berdasarkan Riset Kesehatan Dasar (Riskesdas) 2018, di Indonesia terdapat 30,8 persen anak mengalami stunting. (https://pusdatin.kemkes.go.id/resources/download/pusdatin/buletin/Buletin-Stunting-2018.pdf).

Kabupaten Banyumas merupakan kabupaten/kota yang termasuk seratus besar wilayah dengan angka stunting tertinggi di Indonesia (Dinas Kesehatan Kabupaten Banyumas). Bahkan angka stunting di Banyumas mencapai 24 persen dari sampel 300 balita di Banyumas, sedangkan standar WHO maksimal 20 persen. Dinas Kesehatan Kabupaten Banyumas merangkum pada tahun 2019 kasus stunting di wilayah Kecamatan Purwokerto Utara cukup tinggi yaitu mencapai 261 kasus. Disebutkan oleh nutrisionis puskesmas tersebut, "Stunting pada anak-anak sangat mempengaruhi kehidupannya di masa yang akan datang, terutama tingkat kecerdasannya biasanya di bawah ratarata anak seusianya. Tentunya ini menjadi perhatian besar karena mereka memang ada dalam wilayah kerja kami."

Mengingat tingginya kasus tersebut, Puskesmas Purwokerto Utara II berupaya untuk menekan angka stunting dengan mendorong pembentukan kelompok pendukung ASI di wilayah kerja Puskesmas Purwokerto Utara II yaitu dengan suatu program inovasi yang bernama "KASIH JERUK PURUT" atau Kader ASI Hebat Jejaring Untuk Kesehatan Purwokerto Utara. Dinyatakan oleh ketua program inovasi, "Salah satu penyebab terbesar dalam kejadian stunting atau bahkan tingginya angka kematian bayi adalah kurangnya asupan ASI eksklusif pada enam bulan pertama kehidupannya." Ditambah lagi Program yang dibentuk pada akhir tahun 2018, memang berawal 
dari masalah cakupan ASI ekslusif di wilayah kerja Puskesmas Purwokerto Utara II yang belum mencapai target yaitu di atas $90 \%$.

Program yang dirintis sejak 29 Oktober 2018 tersebut mengalami dua hambatan dalam pelaksanaanya. Pertama, ibu menyusui belum bahkan tidak dapat memberikan ASI Eksklusif kepada bayi yang berusia 0-6 bulan disebabkan dia harus bekerja. Kedua, ibu menyusui merasa dirinya atau ASI nya tidak mencukupi gizi si bayi sehingga mereka memberikan susu formula kepada bayi yang dianggap dapat memenuhi gizi bayi.

Kegiatan sosialiasi yang dilaksanakan memerlukan tools atau alat bantu untuk memudahkan komunikasi efektif terjadi. Alat bantu komunikasi berupa brosur atau leaflet yang diberikan oleh pemerintah pusat seringkali tidak menyasar secara efektif pada target program karena isi brosur terlalu banyak mengandung unsur tulisan. Sedangkan, berdasarkan observasi dan wawancara awal dengan Ketua Tim Inovasi KASIH JERUK PURUT, Endah Nurkhalida, S.Gz ibu menyusui ratarata berlatarbelakang pendidikan SMA. Mereka lebih menyukai dan lebih memahami informasi jika materi yang diberikan banyak menggunakan visual atau gambar. Hal tersebut disebabkan literasi ibu menyusui setingkat SMA relatif kurang.
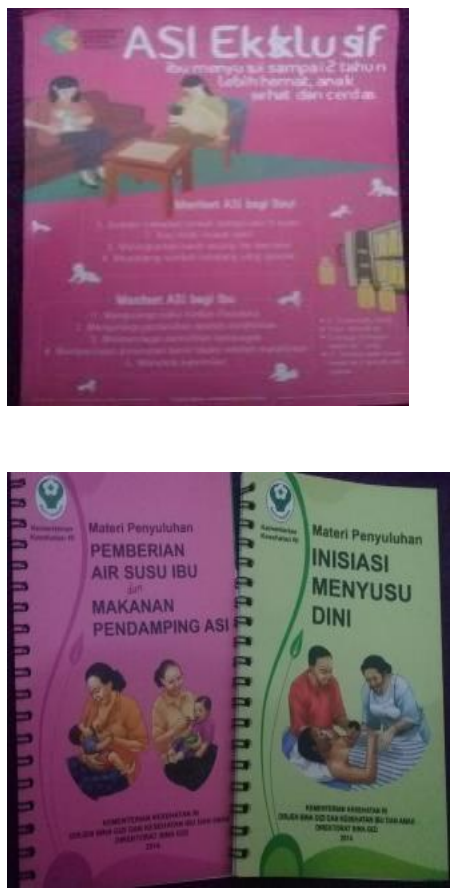
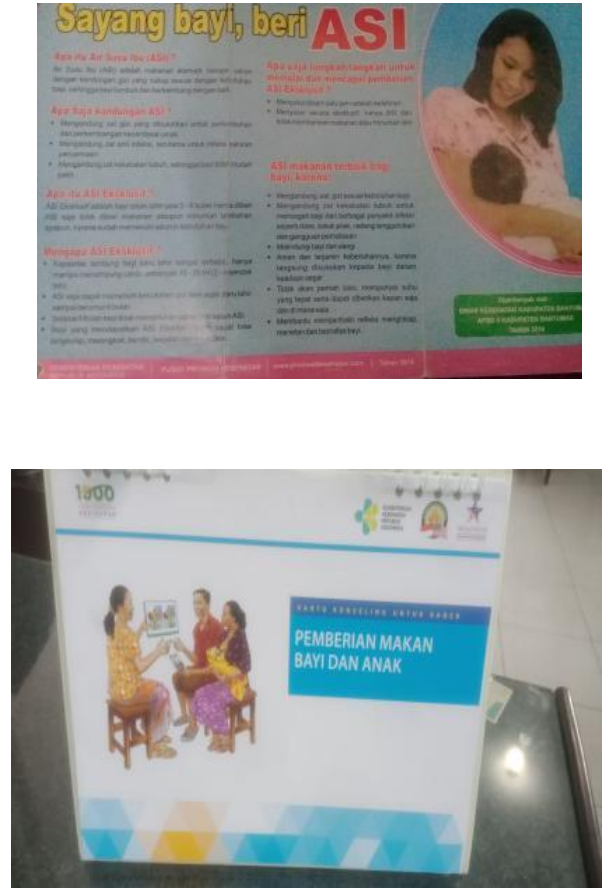

Gambar 1. Alat bantu komunikasi

Menilik dari temuan di atas, maka penting adanya sebuah alat bantu komunikasi untuk menunjang keberhasilan komunikasi. Penelitian yang berjudul Knowledge, Attitude \& Practice of Exclusive Breatsfeeding among Mothers in Techiman, Ghana menunjukkan bahwa penyedia layanan kesehatan merupakan tokoh kunci dalam program pemberian informasi dan edukasi mengenai ASI Eksklusif pada ibu menyusui. Pengaruh sosial dan agama juga memiliki peranan yang signifikan dalam membentuk perilaku pemberian ASI terutama persepsi tentang ASI Ekslusif. Faktor yang memungkinkan memengaruhi perilaku tersebut di antaranya adanya dukungan suami, keluarga, dan lingkungan sosial. Kekuatan pendorong bagi suksesnya pemberian ASI Eksklusif selama enam bulan adalah motivasi diri dan edukasi mengenai ASI Eksklusif, walau dihadapkan dalam ketidaknyamanan dan waktu cuti yang pendek. Demi keberhasilan program pemberian ASI Eksklusif tersebut, maka dibutuhkan kebijakan yang mempromosikan ASI Eksklusif, fasilitas, dan dukungan kepada ibu menyusui. (Boateng, 2018) 
Artikel lain yang berjudul Underweight, Stunting and Wasting among Children in Kilimanjaro Region, Tanzania; a Population-Based Cross-Sectional Study membahas mengenai faktor resiko yang terkait dengan anak-anak yang kekurangan berat badan, stunting, dan bayi berusia 0-24 bulan yang kekurangan gizi di enam distrik di wilayah Kilimanjaro. Sebanyak 1.870 anak-anak dilibatkan dalam penelitian tersebut dan terlihat bahwa prevalensi gizi buruk pada ke-enam wilayah yang dimaksud cukup tinggi yaitu $41,9 \%$ terhambat pertumbuhannya. Dalam penelitian tersebut tingkat pendidikan ibu dikaitkan serta strategi komunikasi dengan anak-anak dan bayi yang kekurangan berat badan dan stunting. (Mgongo, 2017)

\section{PELAKSAAAN DAN METODE}

Program pengabdian kepada masyarakat disesuaikan dengan kebutuhan mitra agar tepat sasaran. Dimulai dengan dengan identifikasi dan memetakan masalah dilanjutkan dengan merumuskan kebutuhan yang dibutuhkan mitra. Terindentifikasi bahwa mitra membutuhkan media atau alat bantu komunikasi bergerak yang belum dimiliki oleh mitra.

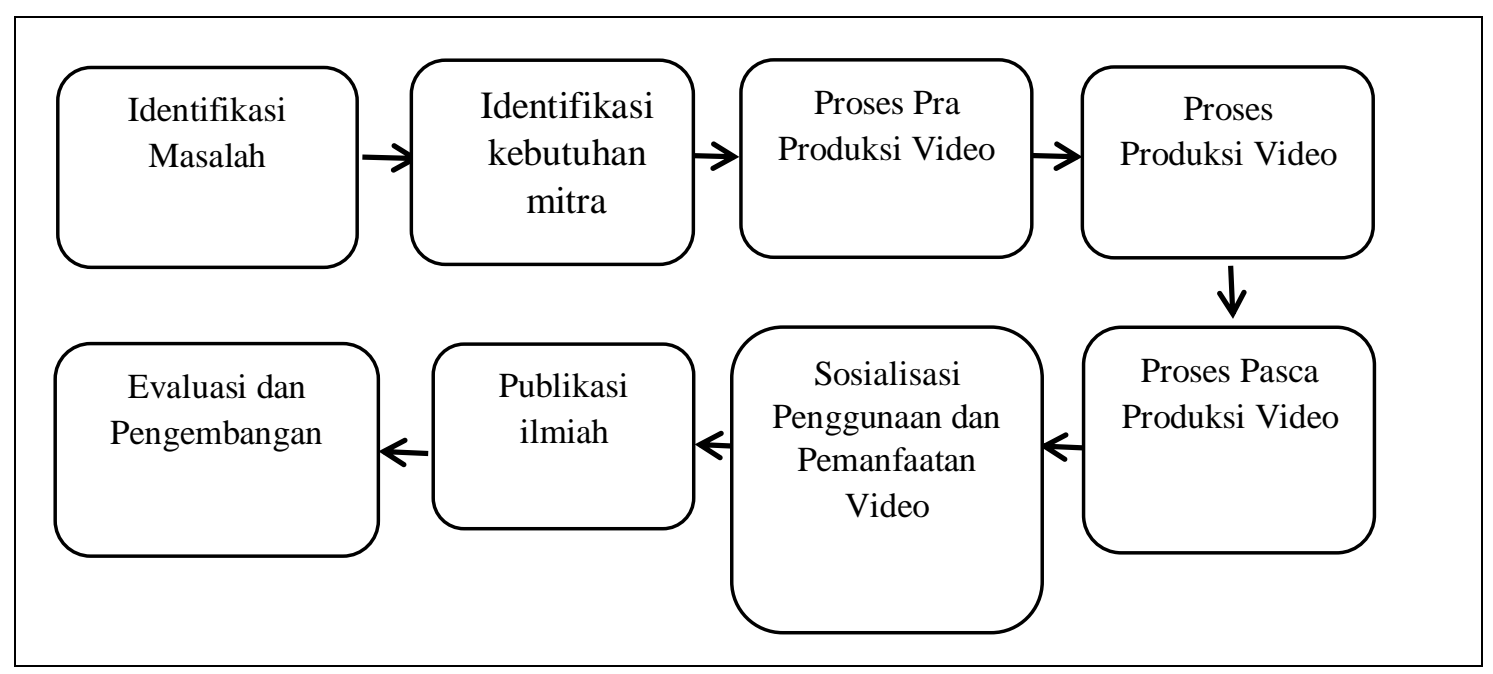

Gambar 2. Bagan Metode Pelaksanaan PKM

Kebutuhan institusi akan gambar bergerak ditindaklanjuti dengan membuat video dengan menggunakan after effect motions graphics. Pembuatan video ini melalui proses pra produksi, produksi dan pasca produksi. (Madcoms, 2013). Pada tahap pra produksi, diperlukan pengumpulan data dan informasi, baik dari majalah, buku atau menanyakan langsung kepada yang ahlinya, perancangan krangka karakter, properti dan background, pembuatan storyboard, persiapan aplikasi yang dibutuhkan. Tahap produksi ditandai dengan pembuatan video, perekaman narasi, dan membuat lagu. Akhir produksi dilanjutkan dengan pasca produksi yaitu membuat desain grafis menjadi sebuah animasi menggunakan Adobe After Effect, menambahkan narasi, sound effect dan musik kemudian di lanjutkan dengan evaluasi akhir dan melakukan konsultasi kepada pihak kader ASI mengenai informasi dan konten dalam video tersebut. Tahap akhir adalah rendering ke dalam format (*.H264, *.mp4 ). Kemudian sosialisasi penggunaan dan pemanfaatan video dilakukan setelah melalui tahap pasca produksi.

\section{HASIL DAN PEMBAHASAN}

Ketua program inovasi Kasih Jeruk Purut menghendaki sebuah media visual yang bergerak untuk memudahkan kader memberikan penyuluhan dan konseling. Media tersebut berupa video animasi yang memuat tentang bagaimana aliran produksi ASI, kandungan ASI serta contoh-contoh perlekatan antara ibu dan bayi dalam proses menyusui. Media konvensional yang selama ini diproduksi oleh pemerintah pusat maupun daerah dirasa kurang mengenai sasaran, apalagi saat penyuluhan. Media komunikasi berupa visual akan lebih menarik perhatian serta mampu memberikan pemahaman lebih baik bagi para ibu. 
After Effects Motion Graphics atau alat bantu/alat peraga berguna untuk mempermudah jalannya proses penyuluhan. Alat peraga ini juga mampu membantu menarik perhatian masyarakat untuk memahami informasi yang disampaikan oleh konselor. Edgar Dale membagi alat peraga dalam sebuah kerucut dengan sepuluh tingkatan, pertama kata-kata, tulisan dan rekaman, film, televisi, pameran, field trip, demonstrasi, sandiwara, benda tiruan dan benda asli. (Jackson, 2016)

Luaran yang diharapkan dari pelaksanaan program Kasih Jeruk Purut ini adalah meningkatkan pengetahuan ibu yang menyusui mengenai pentingnya memberikan ASI Eksklusif kepada bayi yang berusia 0-6 bulan melalui After Effects Motion Graphics yang tepat. Dengan meningkatnya pengetahuan ibu menyusui, mereka dengan sadar melaksanakan program ASI Eksklusif. After Effects Motion Graphics yang dimaksud dalam program ini berupa motion graphic yang memuat konten program KASIH JERUK PURUT yang disesuaikan dengan target program. Berikut ini gambaran teknologi yang diterapkembangkan:

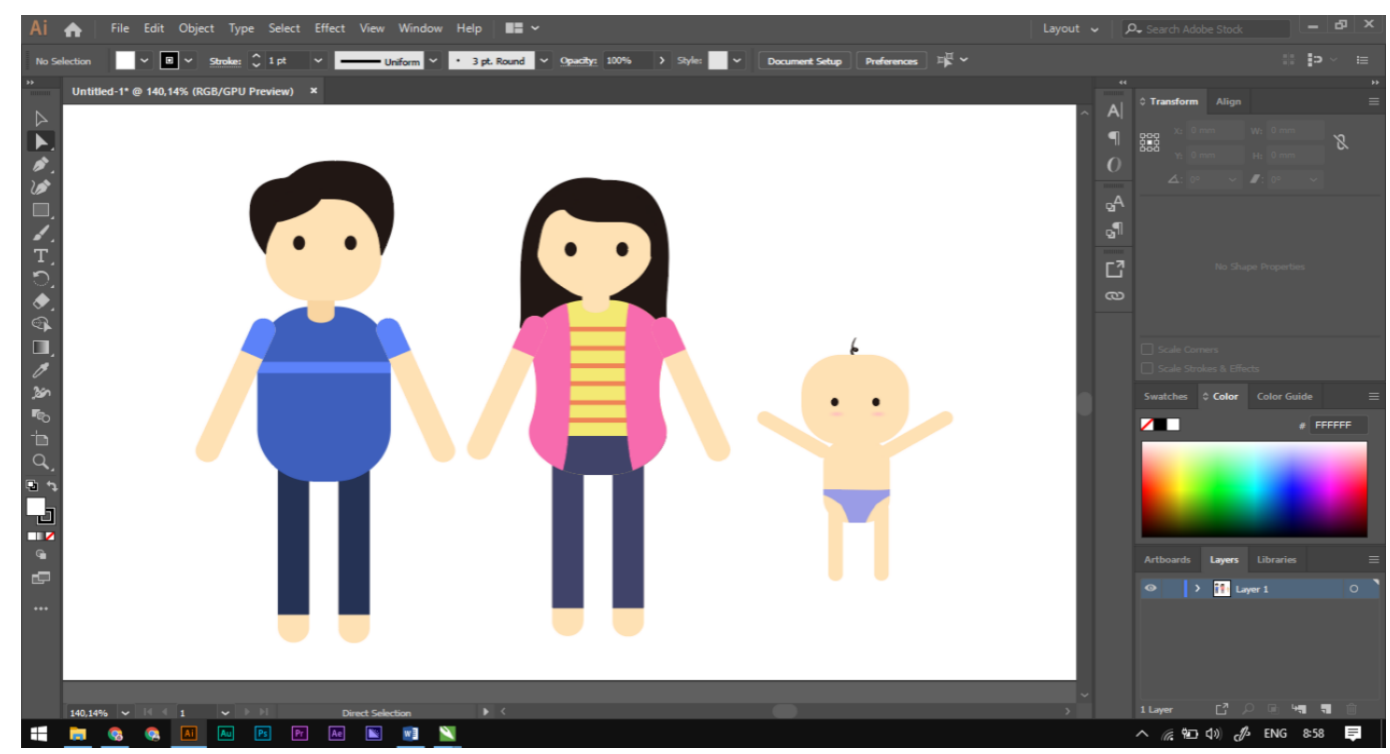

Gambar 3. Contoh Desain Karakter

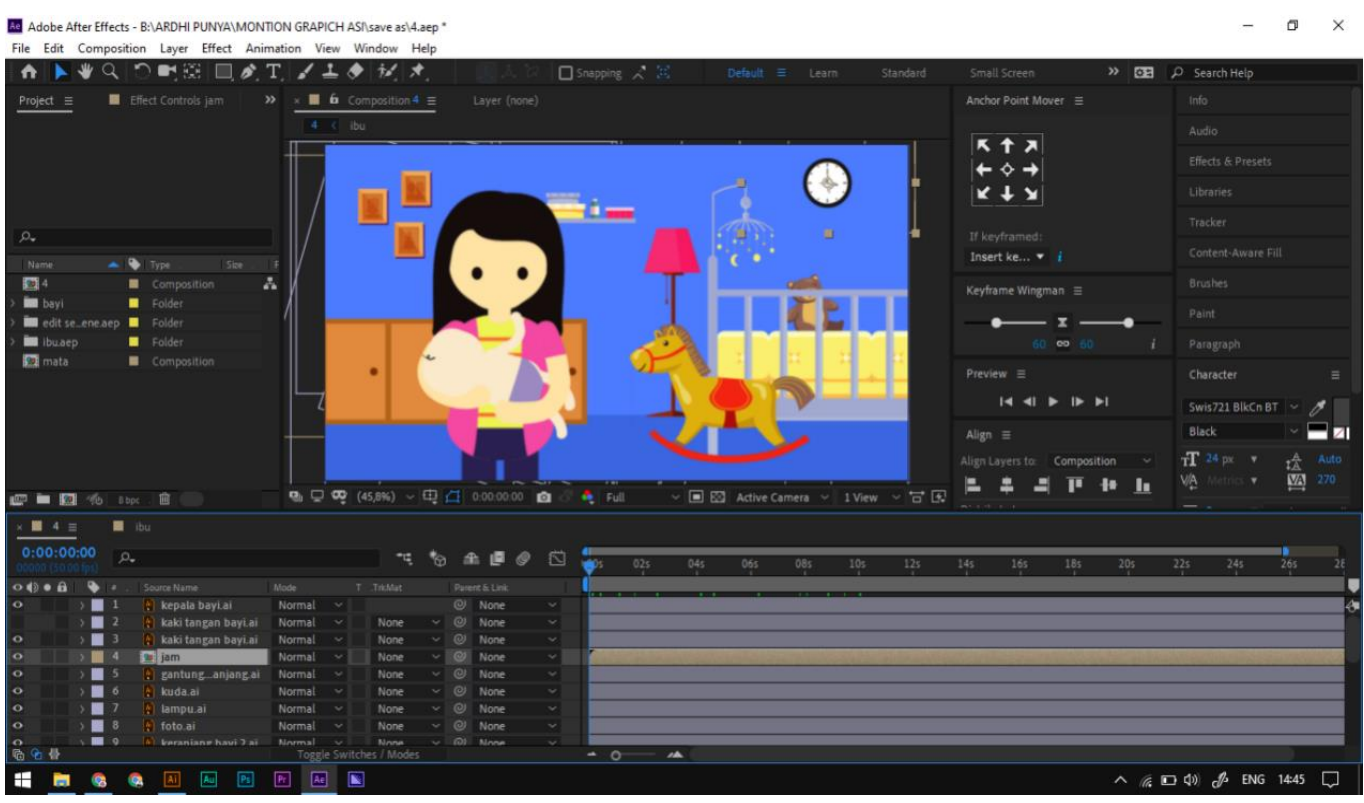

Gambar 4. Contoh Desain yang Akan di Animasi pada Adobe After Effects.

Worksheet pada After Effects ini merupakan bagian paling penting mulai dari animasi objek serta karakter yang sudah dibuat pada adobe illustrator, penambahan narasi dan musik. Efek ini membuat konten tersebut lebih menarik dan mudah dipahami atau diserap kaum ibu menyusui 
dengan latar belakang pendidikan SMA atau sederajat. Sebelum pelaksanaan program ada hal yang terlebih dahulu dilakukan, adanya pembuatan ide dan konsep bertujuan untuk menargetkan sasaran yang akan dituju. Persiapan ini juga meliputi observasi tempat dan pengumpulan data. Perencananaan desain media pelaksanaan untuk program KASIH JERUK PURUT ini berupa rancangan Motion Graphics yang sederhana yang memuat konten cara menyusui yang benar dan makanan yang membantu untuk lancarnya ASI secara cukup. Pada tahap ini, pembuatan Motion Graphics untuk menunjang program ini yaitu meliputi :

a. Pencarian materi tentang pemberian ASI Eksklusif.

b. Pembuatan story board tentang pemberian ASI Eksklusif.

c. Perancangan karakter, properti dan backgound.

d. Membuat desain konten menggunakan Adobe Illustrator.

e. Menganimasikan desain dan objek yang telah dirancang menggunakan Adobe After Effects.

f. Menambahkan narasi serta mencocokan narasi agar sesuai dengan visual animasi.

g. Compositing, memasukan audio dan narasi untuk memperjelas motion graphics tersebut.

h. Rendering adalah merubah dari file mentah ke bentuk file siap tayang contohnya kedalam bentuk video (*.mp4, *.H264, *.mov, dll).

i. Color Grading animasi jika di butuhkan.

Konsultasi dengan Ketua Program Kasih Jeruk Purut dan Kader ASI sangat dibutuhkan sebelum video ini disosialisasikan pada masyarakat. Pada tahap ini tim PKM mensosialisasikan produk untuk mendapatkan masukan dari mitra mengenai hal-hal apa sajakah yang perlu ditambahkan atau dikurangi dari tampilan produk. Pada beberapa hal ada yang perlu direvisi, seperti suara kurang terdengar karena backsong terlalu keras. Konten sudah cukup baik dan jelas, hal ini karena Kader ASI juga menguji coba kepada beberapa sampel ibu menyusi dan mereka menyatakan bahwa informasi yang disampaikan sederhana dan cukup memberi pemahaman.

Satu minggu setelah proses revisi, video mulai dapat disosialisasikan kepada mitra secara resmi. Mitra dapat meneruskan kepada konselor dan kader ASI untuk dapat dipergunakan sebagai alat bantu yang dapat menunjang keberhasilan program komunikasi, informasi dan edukasi KASIH JERUK PURUT. Video ini pun dapat disebarluaskan melalui sosial media kepada ibu hamil dan menyusui di wilayah kerjanya. Diharapkan pemanfaatan video ini tidak berhenti untuk sekedar pemberian informasi tetapi pada perubahan perilaku ibu dalam proses pemberian ASI kepada anaknya. Video ini nantinya akan bersama-sama dengan media komunikasi lainnya membantu strategi komunikasi program. Setelah melihat hasil akhir dari pemanfaatan video ini, maka tim PKM akan mengevaluasi sejauh mana produk tersebut dipahami oleh masyarakat sasaran.

\section{PENUTUP}

\section{Simpulan}

Kegiatan pengabdian kepada masyarakat ini berangkat dari kebutuhan mitra akan sebuah alat bantu komunikasi yang berisi tentang pentingnya pemberian ASI Eksklusif pada bayi. Selama ini alat bantu yang digunakan berupa brosur atau leaflet yang sarat dengan tulisan. Dianggap kurang menarik dan kurang menyasar, maka mitra membutuhkan sebuah video atau gambar bergerak yang lebih menarik. Hal tersebut ditangkap oleh tim pengabdian masyarakat dari Program Studi Ilmu Komunikasi Universitas Amikom Purwokerto untuk menindaklanjuti dengan membuat video menggunakan after effect motion graphis.

Kegiatan ini berjalan cukup lancar dengan revisi teknis yang tidak berarti. Video ini cukup membantu Kader ASI Hebat Jejaring untuk Purwokerto Utara 2 dalam berkomunikasi dengan ibu hamil dan ibu yang kesulitan dalam kegiatan menyusui. Setelah diujicobakan kepada ketua program, kader ASI dan delapan ibu menyusui, didapatkan hasil bahwa mereka merasa terbantu dengan adanya media video tersebut. Tidak berhenti sampai si sini, tentunya para kader ASI dapat menggunakan video ini ketika melakukan penyuluhan secara berkala. Bahkan dapat disebarluaskan dengan menggunakan sosial media kepada ibu hamil dan ibu menyusui sebagai tindak lanjut program KASIH JERUK PURUT. 


\section{Saran}

Evaluasi mengenai tingkat keberhasilan video tersebut diharapkan dapat menjadi kajian pada studi selanjutnya. Terima kasih atas pihak-pihak yang telah membantu, terlibat, dan berperan dalam terselenggaranya kegiatan pengabdian kepada masyarakat ini, yaitu Puskemas Purwokerto Utara 2 dan Unversitas Amikom Purwokerto serta masyarakat .

\section{DAFTAR PUSTAKA}

Jackson, Jon. (2016). Myths of Active Learning: Edgar Dale and the Cone of Experience. Journal of the Human Anatomy and Physiology Society Volume 20, Issue 2 April 51-53.

Madcoms. (2013). Kupas Tuntas Adobe After Effects CS6. ANDI. Yogyakarta.

Boateng, Mavis F. (2018). Knowledge, Attitude and Practice of Exclusive Breastfeeding among Mothers in Techiman, Ghana. Thesis.

Mgongo, Melina. (2017). Underweight, Stunting and Wasting among Children in Kilimanjaro Region, Tanzania; a Population-Based Cross-Sectional Study. International Journal of Environtmental Research and Public Health, 14(5).

Situasi Balita Pendek (Stunting) di Indonesia. Buletin Jendela Data dan Informasi Kesehatan.URL https://pusdatin.kemkes.go.id/resources/download/pusdatin/buletin/Buletin-Stunting2018.pdf 